\title{
'I will know it when I taste it': trust, food materialities and social media in Chinese alternative food networks
}

\author{
Leigh Martindale $^{1}$ iD
}

Accepted: 12 September 2020 / Published online: 13 October 2020

○) Springer Nature B.V. 2020

\begin{abstract}
Trust is often an assumed outcome of participation in Alternative Food Networks (AFNs) as they directly connect producers with consumers. It is based on this potential for trust "between producers and consumers" that AFNs have emerged as a significant field of food studies analysis as it also suggests a capacity for AFNs to foster associated embedded qualities, like 'morality', 'social justice', 'ecology' and 'equity'. These positive benefits of AFNs, however, cannot be taken for granted as trust is not necessarily an outcome of AFN participation. Using Chinese case studies of AFNs, which are characterised by a distinct form of trust pressure - consumers who are particularly cynical about small scale farmers, food safety and the organic credentials of producers - this paper highlights how the dynamics of trust are in constant flux between producers and consumers. I suggest that it is the careful construction of the aesthetic and multi-sensory qualities of food, which is often celebrated via social media, that human centred relations in Chinese AFNs are mediated. This leads to two key conclusions: first, that the key variable for establishing trust is satisfying the consumer's desire for safe (i.e. "fresh") food; and second, the materiality of the food and the perception of foods materiality (especially through social media), must both be actively constructed by the farmer to fit the consumer's ideal of freshness.
\end{abstract}

Keyword Alternative food networks $\cdot$ Social media $\cdot$ China $\cdot$ Food materialities $\cdot$ Trust

\section{Abbreviations \\ AFN Alternative Food Networks \\ PGS Participatory Guarantee System (PGS}

\section{Introduction}

In 2008, China saw its most high-profile food safety scandal with contaminated melamine baby formulae causing 6 infant deaths and nearly 300,000 cases of kidney problems (Yang 2013). This incident was the tip of the iceberg in regard to food safety scandals and served as a moment of food 'awakening' for the growing Chinese middle class, consolidating an emerging feeling of distrust towards general food quality and food certification (Yan 2015; Scott et al. 2014; Wang et al. 2015). This moment has helped drive a new domestic market for safe, green and organic food in China, which in light of the Covid-19 pandemic and its suspected wet market

Leigh Martindale

leighmartindale@yahoo.co.uk

162 Rhos Road, Rhos-on-Sea, Conway LL28 4RY, Wales origins, is only likely to accelerate interest in alternative food provisioning channels. As a response to these food scandals, a growing number of direct marketing networks have begun to emerge in China which are reminiscent of those short food supply chains movements or alternative food networks (AFNs) found in Europe and the US i.e. community supported agriculture (CSA), organic farmer's markets, buyers' clubs etc. (Shi et al. 2011; Klein 2014; Si et al. 2015). ${ }^{1}$ Typically, AFNs are practices that refer to a diverse range of initiatives involving the production, distribution and retail activities of food that are distinct from the food processes synonymous with big agri-business and 'supermarketisation' (Goodman et al. 2012; Harris 2010; Jarosz 2008; Whatmore et al. 2003).

In China, what counts as an 'alternative' food network (AFN) is less apparent in comparison to the global north. The variety of food procurement options in China-e.g. wet markets, street stalls, the myriad collection of small farmholdings throughout peri-urban and rural China, food-centred festivals and the wide practise of edible gift exchanges

\footnotetext{
${ }^{1}$ China's first internationally recognised Community Supported Agriculture (CSA) farm, 'Little Donkey farm' in Beijing, also began in 2008 .
} 
(Scott et al. 2018) - has made the distinction of alternative food networks in China less stark than in the case of AFNs based in North America or the UK (Martindale et al. 2018). However, the recent emergence of larger monoculture-based farms and the massive levels of supermarketization in China over the last 40 years has, at least from the vantage point of China's new middle class, given credence to the 'alternative' term engendered by these new forms of food procurement practices centred on food safety and "greener" farming techniques (Shi et al. 2011; Si et al. 2015; Krul and Ho 2017). Indeed, these networks in China do emphasise forms of direct exchange between consumers and producers and are, at the very least, suggestive of a promise of difference that is 'alternative' and akin to their global north counterparts. ${ }^{2}$

AFNs in China, however, do differ to their global north counterparts in various ways, with "Chinese AFNs [being] more narrowly built upon safety of food and not genuine mutual trust" perhaps the most significant (Si et al. 2015, p. 303). Indeed, the commonplace food scandals regarding milk powder, cooking oil, recycling of out-of-date meat, contamination of egg-based products and staples like rice being compromised, means that the prism through which AFNs in China are perceived becomes inherently tied with up with trust (Wang et al. 2015; Yan 2015). This increased emphasis on trust has meant that assuming direct exchange between producers and consumers guarantees, or at least encourages, a form of reconnection is especially fraught.

The Chinese context of AFNs, due to these pressurised producer-consumer interactions, presents an apt context to explore how trust is negotiated in these enterprises. As direct exchange has to occur when cynicism is the default position between buyers and small scale local farmers, this poses interesting questions about how the trust relationship between producers and consumers functions, especially if the transformative potential of AFNs relies on the transfer of embedded qualities, such as 'morality', 'social justice' and 'equity'. I use the term 'trust pressure' to describe this additional burden placed on Chinese AFNs and to show how this pressure forces Chinese AFNs to emphasise the quality (i.e. safety) of their produce. This suggests that the transformative potential of the novel AFN consumer-producer relationship lies not in assumed 'moral' outcome of AFN participation, but through pragmatic strategies aimed to relieve trust pressure; strategies which tend to emphasise food's material qualities - namely the sensory and aesthetic qualities of food (see Turner 2014) - and often relies on social media to bring them to the fore.

The rest of the paper is structured as follows. Next, I outline the current literature that discusses the assumed 'novel'

\footnotetext{
2 For a broader defence of the term 'alternative' in AFN literature see Le Velly (2019) and Rosol (2020).
}

relationship between producers and consumers in AFNs before I examine the current Chinese AFN literature and the wider Chinese context of trust. I follow this with a description of the fieldwork and the methodology used. Based on these fieldwork observations, I then present my findings on how trust pressure plays out in a Chinese AFN context, highlighting the different strategies AFN participants utilise to build trust. This section also shows how trust is often navigated through a celebration of the material qualities of food, an attribute which is facilitated primarily by social media. A discussion of the findings is presented next, which is then followed by my conclusions regarding the implications of trust on foods' material qualities.

\section{Novel relationships in AFNs}

A key attribute of AFNs is the way they bring producers and consumers into closer proximity and has prompted others to refer to them as 'short food supply chains' (Renting et al. 2003). Closer proximity between producers and consumers is said to encourage a process that socially (re)embeds the farming and agricultural sector with forms of "morality" (Sage 2003, p. 49) thus creating trust. This 'trust', that forms between producers and consumers during direct exchange, can be understood as the quality which allows "individuals involved in interactions [to] expect others to follow 'normal' patterns and routines in social life so that the continuity of social reality can be taken for granted" (Zhang et al. 2016, p. 271; Giddens 1990). In other words, trust is tied up with aspects of vulnerability and risk and shapes people's expectations of what constitutes normal everyday life. In AFNs, then, trust is formed from both the buyer and the seller expectations being met (Lee 2000). The buyer expects that the seller is producing quality, safe, sustainable and ethically produced foodstuffs with specific expertise. From the seller perspective, he or she expects the buyer to accept possibly higher prices; food at a non-standard/supermarket appearance and to have more flexibility and patience regarding the quantity, the seasonality, and the diversity of the produce on sale (Lee 2000).

These buyer-seller expectations, which when fulfilled forms trust, creates the potential for embedded qualities to be transferred alongside the produce. As Roger Lee (2000, p. 139) puts, transactions of direct exchange provide the seller with "not merely the realization of value but the materialisation and extension of regard based on specialised knowledge; for the buyer, [they obtain] status, identity, knowledge and expanded use value". This extension of regard or trust between producer and consumer suggests that forms of moral, social and/or ecological 'reconnections' are also occurring in these alternative food networks (Dowler et al. 2009; Kneafsey et al. 2008; Turner 2011; Hayden and Buck 2012). Thus, during the process of direct exchange between 
producers and consumers, something other than money is passing hands. Notions of social justice, sustainability, risksharing, transparency, locality and-importantly - trust, are also involved in the transaction, thereby transforming and creating new and more moral forms of relationship between buyers and sellers (Ilbery and Maye 2005; Kirwan 2006; Smithers et al. 2008).

These embedded qualities involved in direct exchange have been identified in numerous empirical studies. A recent study by Opitz et al. (2017, p. 189) in Germany, for example, found that consumers involved in AFNs developed an increased awareness for "food (seasonality, cooking/nutrition, housekeeping aspects) and agricultural production (farmers' perspectives and requirements, cultivation)". This potential has tipped commenters to suggest that, at a larger scale, AFNs and related initiatives could foster stronger community relations (Winter 2003) - especially between urban and rural sectors of society (Preiss et al. 2017), help drive a collective environmental and socio-economic consciousness (Pinna 2017), and encourage and enable actors to participate democratically in the system of food provisioning (Hinrichs 2003; Goodman et al. 2012).

Tensions, however, emerge within this process of direct exchange as, alongside these claims of a novel relationship emerging between producers and consumers, empirical research has also highlighted many instances of injustice, non-environmental practices and unequitable relations occurring between AFN participants despite their closer interactions. In some global north AFNs, for example, research showed how participation in AFNs did not guarantee personalised relationships (Allen et al. 2003; Selfa and Qazi 2005; Ostrom and Jussaume 2007). On the farm as well, instances of the exploitation of migrant workers (Allen et al. 2003; Alkon 2013) and interns (Ekers et al. 2016) have also undermined this headline claim that positive, novel, and 'just' relationships are synonymous with AFNs. These tensions regarding the 'embedded' outcomes of direct exchange are perhaps unavoidable, as AFNs must exist and compete within the very fabric of what they are attempting to be alternative to. Indeed, their uneven and partial adoption of some conventional food network characteristics is inevitable to some degree and has prompted some scholars to refer AFNs as being hybrid spaces (Ilbery and Maye 2005; Mount 2012; McClintock 2014).

To date, much of the literature on Chinese AFNs seems to confirm (and heighten) this tension regarding novel relationships in AFNs, with much empirical research arguing that Chinese consumers are only concerned with procuring safe food (for the family), for cultivating healthier, slimmer and more beautiful bodies (Legget 2017, p. 8), or as a display of 'quality' or 'class' (suzhi) (Klein 2015). Indeed, research has emphasised that the notion of participating in AFNs for social or ecological reasons in Chinese AFNs is largely absent (Klein 2014; Scott et al. 2014). Si et al. (2015), for example, observed that there is often a large disconnect in values between the producers i.e. the managers of the Chinese AFNs - who subscribe more to the embedded social and ecological values engendered by AFNs - and their AFN members. Whilst there is a prevailing tendency that the novelty of Chinese AFNs appears to lie only with the buying of ecologically - and therefore safe-grown produce in a hazardous food system, this does not discount the community building efforts of AFNs that has seen consumers engage in greener and more holistic lifestyles. ${ }^{3}$ In other words, despite direct exchange occurring at times without the ecological and social embeddedness that tends to be automatically assumed and associated with Western AFNs, there still lies a potential for positive outcomes.

Recent AFN scholarship has begun to emphasise this nuance of direct exchange and question this assumption "that consumers join an AFN to learn more about food production, interact face-to-face with producers and avoid the anonymous conventional production system" is erroneous (Thorsøe and Kjeldsen 2016: 171). Indeed, participation can occur in AFNs without necessarily having direct interactions with producers and can be motivated by a range of varying and sometimes mundane factors (Clarke et al. 2008; Albrecht and Smithers 2018). In this sense, "trust in the direct exchange may be as much a predisposition as an outcome; as much an absence of distrust as it is the creation of trust" (Mount 2012: 114; Watts et al. 2018). Participation in AFNs, as with supermarket consumption, already assumes a certain level of trust (or distrust)- one that is liable to fluctuate with subsequent transactions. Although trust is not a guarantee of AFN participation and aspects of 'conventional' producer-consumer relationships is ever present in these organisations, this does not negate the potential for AFNs to develop interesting producer-consumer relationships and help foster positive impacts on the food system (Watts et al. 2018).

Some scholars have begun to emphasise that it is through the material aspects of food, not direct exchange per se, that the novel connections between producers and consumers are formed. For example, Bethaney Turner (2014), through her empirical work with AFNs in Australia, has argued that it is the material qualities of the food that is produced by AFNs that provides the core basis for the 'alternativeness' of AFNs (see also Turner and Hope 2015). This alternativeness becomes possible as food 'materiality', which links food with embodiment and sensuality, suggests food itself can

\footnotetext{
${ }_{3}$ Over time, studies exploring participant engagement in Chinese AFNs have shown a steady increase of social and ecological reasons for participant motivation in these emerging enterprises (Ely et al. 2016).
} 
produce effects (Roe 2006). In other words, it is through the somatic and visceral qualities of food, and perhaps also the tactile spaces of farms (Hayden and Buck 2011), that issues surrounding food production, seasonality, food distribution, cooking styles, recipes etc. can be raised and provoked (Holloway et al. 2007; Turner and Hope 2015). This focus on the materiality of food is an emphasis on the taste, freshness, gustatory pleasure that food can induce, which in turn, affects our attitudes and behaviour towards food accordingly (Turner 2014). Food materiality, therefore, becomes significant in the wider context of AFNs. Indeed, David Watts, Jo Little and Brian Ilbery (2018: 27) have argued that the transformative edge of AFNs lies in "the possibility that the material and semiotic resources that AFN produce may, through the evolutionary process of selection, either displace or be incorporated into, and hence change in some way, the dominant dispositive." For Turner (2014) also, it is through the materiality of food that the human centred relationswhich are currently predicated on exchange of capital—can be altered and adjusted. The following section shows how Chinese AFNs are well positioned to capture the role of materiality as the trust pressure they are under forces them to emphasise these aesthetic and sensory qualities.

\section{The Chinese trust pressure}

The apparent absence of novel reconnections in Chinese AFNs is largely a function of the 'trust pressure' between the producer-consumer relationship. Whilst this trust pressure is particularly heightened in China's food system it also characterises contemporary China in general. China's status as a 'low-trust' society stems in part from its historical legacy as a Confucian society that has been governed by a strong top-down state through means of rule-by-law (Tyfield 2017; Tang 2016). This presence of a prescient authoritarian and potentially capricious government, in tandem with China's under-institutionalization, has forced individuals to rely on networks of personal trust - as formalised through Confucian notions of filial piety - and has encouraged a distrust of strangers (Tyfield 2017, p. 78). This notion of a low-trust society in China is further supported by quantitative survey data that highlights there are three different levels of trust that need to be accounted for in a society: the civil level (the trust persons have towards urbanites, businesspersons and strangers); the communal level (between neighbours, schoolmates, fellow homeowners); and the parochial level (family and relatives). In China, whilst interpersonal trust at the communal and parochial level is relatively high, at civil level it is particularly low in comparison to other countries (Tang 2016, p. 65-66).

Also adding to this historical legacy of low-trust is the effect of Mao's policies of radical socialism. Under Mao, a large divide began to emerge between the urban and rural spheres in China due to the introduction of the $1958 \mathrm{Hukou}$ (Household Registration) system, which introduced legal restrictions on rural to urban migration based on an individual designation as either 'agricultural' or 'non-agricultural'. The result of this policy has led to significant rural unrest and a heavy stigmatisation of 'peasants' who are often labelled by their urban counterparts as "primitive", "uncivilised" and as having "no culture" (Lai 2014, p. 546; Hale 2013; He 2007). Mao's Cultural Revolution (1966-1976) also saw a radical undermining of the social fabric of society. The government-led incentive for people to 'snitch' on each other in this era, in order to signal loyalty to the Party, devastated the levels of social trust in those areas most intensely affected by the revolution (Wu 2016).

This historical legacy has meant China has always had a general predisposition towards distrusting strangers, especially across the urban-rural divide. A disposition which has only been consolidated by China's recent experience of rapid industrialisation and modernising over the last forty years and its embracing of neoliberalism and 'bottom line' economics. Indeed, the rapid, intense and largely unregulated industrialisation in China, which without developed civil institutions and a comprehensive welfare state, has undermined further the levels of social interpersonal trust in contemporary China (Tyfield 2017: 151).

It is, perhaps, in the food industry where this contemporary trust pressure in China becomes its most visible, for eating is an act that already requires an intense form of trust. As eating involves the incorporation of the 'outside' world with the 'inside' world of the body, this particular action will always be intimately steeped in issues of anxiety and risk (Kneafsey et al. 2008). That the industrial food process is now also breeding "symbolic danger", in the form of chemicals and trace elements, only enhances the issues of anxiety and risk involved with eating (Kneafsey et al. 2008, p. 13).

In China this 'symbolic danger' has become a lot more tangible due to its yield-centred approach to agriculture that is based on investing in chemical fertilisers (Jiao et al. 2018), high yield seed variations (Ely et al. 2016) and intensive industrial processes affecting food quality (Schneider and Sharma 2014). This form of agricultural intensification in China has been a political priority for decades due to changing diets-higher demands for meat (and maize for feedstock) - and the decreasing availability of arable land (Jin et al. 2017). The environmental and social costs of this policy, which began over 30 years ago, are now being acutely felt in contemporary China with headlines concerning the overuse of pesticides (Xu 2017) and the high concentrations of industrial heavy metals found in the soil (He et al. 2013) commonplace.

Food safety has since become a regular top issue of concern by the Chinese public due to the contamination scandals which are frequently occurring across the food 
industry - with even staple foods like rice, maize/corn and pork being regularly affected (Zhang and Qi 2019; Yan 2015). ${ }^{4}$ Matthew Kahn and Siqi Zheng (2016, p. 43), for example, have highlighted how $44 \%$ of rice samples in Guangzhou were found to contain poisonous levels of cadmium. Instances regarding food fraud in China are also of alarming frequency (Kendall et al. 2019); a phenomenon that has also massively compromised trust in organic food labelling (Veek et al. 2010). ${ }^{5}$ The 'perceived' uncontrolled spread of GM crops is also compounding this issue of trust regarding food (Ely et al. 2016).

This lack of trust with food procurement is also coupled with the absence of altruistic consumer narratives like 'buy local' or 'ethical consumerism' (Klein 2009; Scott et al. 2014). These narratives, which have a longer and more established tradition in the global north (Malpass et al. 2007), and have alleviated, to some degree, the burden that AFN producers in Europe and North America have to reach out and convince consumers of their 'authenticity' or 'trustworthiness'. Furthermore, AFNs in the global north can take trust for granted as "consumers consistently and overwhelmingly indicate a willingness to grant trust to farmers as a generic group, and exceptional levels of trust to small and/ or local farmers" (Mount 2012, p. 114; Watts et al. 2018). In China, there is instead a heightened scepticism towards the rural and small scale farmer (Lai 2014) - which "due to accounts of rural producers being purposefully careless or deliberate regarding the food adulteration of produce that is intended for consumption in the city" is unsurprising (Yan 2015).

These frequent and numerous food issues in China have led to 'what can we eat?' becoming one of the most commonly raised question on social media websites by Chinese netizens (Wang et al. 2015; Lam et al. 2013) - and this is despite China's control of social and mainstream media that is averse to fomenting forms of social panic (Paull 2008, p. 5). Some countries-Japan for example-have even banned Chinese food imports due to food safety fears (Paull 2008) ${ }^{6}$. These food safety incidents, which have been regularly exposed over the past two decades, show no signs of declining (Yan 2015).

The state's response to this food crisis has been to deploy rigorous top-down regulations and market-based mechanisms (Zhang and Qi 2019; Gaudreau 2019). The revisions to the food safety law in 2015 , laws which were only initially

\footnotetext{
${ }^{4}$ Wikipedia also has a page dedicated to the recording of Chinesebased food scandals (see: https://en.wikipedia.org/wiki/Food_safet y_incidents_in_China).

${ }^{5} 60,000$ fake/fraudulent food cases were reported by the Xinhua News Agency in 2007 (Veeck et al. 2010).

${ }^{6}$ In 2012, Germany also had to recall strawberries they had imported from China due to contamination issues (Zhang and Qi 2019).
}

formalised in 2009, have been heralded as being one of the most stringent globally (Sim and Yang 2016; Zhang et al. 2016). This increased emphasis on inspection and regulations, however, has been designed as a one-model-fits-all approach that suits the modernising and large-scale mainstream channels of the food network whilst undermining small-scale food producers unable to conform to complicated food law reforms (Zhang and Qi 2019). These measures have not only failed to push larger-scale enterprises from engaging in structural reform, but have squeezed the genuine alternative, traditional and small scale 'ecological' or organic food networks which are struggling to survive (Zhang and Qi 2019). Furthermore, the 2015 food safety law also seems to be failing to communicate the new regulatory reforms to consumers, and has been largely inadequate at ensuring the transparency and availability of information regarding food quality and safety measures, impinging trust further (Zhang et al. 2016; Wang et al. 2015).

The collapse of consumer confidence in food institutions across China has led to a "dramatic bottom-up movement of social self-protection" (Zhang and Qi 2019, p. 115). For many rural producers across China, these food safety issues have meant adopting a 'one family two system' approach to farming in which they divide their crops into two sections, one set grown with more ecological based methods for self and family consumption, and the other larger portion grown in bulk for use as cash crops (Lin et al. 2019). Consumers have also sought self-protection-for those who have the wealth, means and the time to do so-namely by cultivating personalised forms trust with producers in small scale informal or alternative food networks in order to resolve, or at least alleviate, food based anxiety (Kendall et al. 2019; Wang et al. 2015). As a consequence, "the cultivation of trust through these AFNs emerges as an entry point for critical examination of the commodification of food and other social relations in modern Chinese society" (Zhang and Qi 2019, p. 121). In the context of AFNs, then, trust pressure refers to the various societal and cultural difficulties consumers and producers have in reconnecting, despite the proximity lent by direct exchange.

\section{The setting and research methodology}

My fieldwork site(s) were based in and around the Guangzhou \& Shenzhen metropolitan area also known as the 'Pearl River Delta' in Guangdong province. These cities are located in Guangdong province, a region of China that has a relatively long history of ecological agriculture in comparison to other provinces in China (Riggs 2005). Guangdong's environment is especially suited towards organic or ecological forms of farming and as a region, farming in Guangdong has never been subsistence based due to its hilly topography and climate. Thus, unlike other provinces, 
agriculture in Guangdong has historically been strongly market-orientated and as such, has tended to focus more on producing sub-tropical fruits and differentiating its produce by quality (Riggs 2005 , p. 48). In response, the state government of Guangdong, more so then others, has granted more autonomy for its farmers to make 'ecological' production decisions by recognising the importance of the 'quality' produce market in Guangdong (Riggs 2005). ${ }^{7}$ Furthermore, important scientific institutions in Guangdong like the South China Agricultural University and the Guangdong Natural Science Foundation have gone against the grain and prioritised ecological agriculture as a long-term research avenue, with a particular focus on participatory agricultural research (Riggs 2005).

During my two 10 month fieldwork periods in China, both between late 2015 and early 2017, I visited 12 AFNs and 'ecological' farms which were located on the outskirts of Guangzhou. ${ }^{8}$ The bulk of my research was centred around two AFNs: a twice-a-month organic farmers market hosted by the platform 'Bringing City and Country Together' (ChengXiangHui) and the largest CSA farm in China 'Four Season Share' (SiJiFenXiang).

'Bringing City and Country Together' defines itself as a 'Public Service Platform' and is located in the centre of Guangzhou city (Taojin). Five AFN leaders initially formed the platform in September 2010, after coming to the conclusion that they needed to pool their resources together in order to market AFN membership efficiently and to promote 'organic' living in Guangzhou. In December 2010 they defined their three mission statements: (1) to promote mutual support between the urban and rural areas; (2) to aid small farmers in developing organic farming; and (3) to promote a low carbon lifestyle in the cities. Since January 2011 ChengXiangHui has held an organic farmers market event monthly which showcases natural and ecological ingredients, organic products, fair trade products, environmentally friendly household items and handmade products. In sum, the platform hopes to provide urban residents a direct access to nutritious and "authentic" food while protecting farmers from less developed areas from exploitation. They also aim to increase the awareness of ethical consumerism amongst people in the cities and to provide help and support to those

\footnotetext{
7 The local state in Guangdong was already predisposed to endorsing ecological agriculture formally due to the advantages this agriculture method has in regards to soil erosion, an issue that plagues most of China, especially in provinces prone to flooding like Guangdong (Riggs 2005).

${ }^{8}$ For the purposes of this study AFNs were loosely defines as agricultural enterprises employing more "ecologically-based" agricultural techniques (i.e. not using chemical fertilisers or pesticides) and were directly in contact with their consumer base.
}

famers taking part in organic farming with the ideals of CSA.

During my residency in Guangzhou, I was a regular shopper and participant at ChengXiangHui. I took this opportunity to establish relationships with the vendors, farmers and customers at the market and it is from this base I drew the majority of informants for my interviews. Through this platform I was able to visit some of the organic farms that surround Guangzhou, understand the lives of those involved at the platform and take part in their peer-based certification scheme, the Participatory Guarantee System (PGS). ${ }^{9}$

'Four Season Share' is located to the north of Shenzhen (the north-east of Guangzhou) in Zhoutian village (close to Huizhou city). The farm covers 13.3 hectares and includes 28 large greenhouses (covering approximately 3.5 hectares). This organically certified farm is the owner's third attempt at creating a large-scale working CSA farm in China (his other attempts never became financially viable), and in terms of membership, delivering to approximately 1400 families, is currently the largest in China. The owner is well known and respected in China's 'organic' circles and, for many, his CSA farm -its business and management model - is the one to aspire to.

I spent two weeks during April 2016 at Four Season Share farm. During my stay I helped in many of the farm's daily tasks and, in return, was housed and fed. Staying here provided me with the opportunity to meet and talk with many people who worked in the different departments across the farm; this included a meal with the owner during one of his business dinners at the farms restaurant. Although I could not have any formal in-depth interviews during my time on the farm - due to the absence of a translator - with my broken Chinese and their pigeon-English I was able to have informal conversations that contributed to my research diary.

I used a variety of qualitative methods to conduct my research in order to capture the diversity of ways participants experienced AFNs. The methodology comprised of semi-structured interviews, participant observation of AFNs (during my stay at Four Season Share) and a monitoring of the social media presence of AFNs-in particular the social media dialogue between AFN owners and their members. I found my informants through use of snowball sampling and frequently relied on a research assistant due to my limited Mandarin ability.

Typically, I required my research assistants to ask my interview questions, and follow-up questions, whilst I recorded the exchange. After conducting the interviews, I

\footnotetext{
${ }^{9}$ PGS is a peer review scheme whereby farmers and vendors visit each other farms to ensure organic methods are being employed, and to give advice on how they can be improved further. PGS is found the world over and is a common scheme adopted by small scale farmers who cannot afford official organic certification.
} 
was also dependent on my assistants for transcribing and translating the interview data. This led to some interesting predicaments surrounding my research as translators themselves become producers of research data, influencing the analysis via their own personal identity and life experiences (Simon 1996). To account for this hybrid role of the translator I recognised the translator as an additional informant, not just as an objective observer. I did this by ensuring the translator was familiar with both cultures (Cortazzi et al. 2011, p. 521), taking time to also recognise and understand the translator's personal opinion and feelings towards the research topic (Temple and Young 2004) and undertook the data analysis as 'a side-by-side procedure, in which the researcher and the translator discuss possible wordings' (Van Nes et al. 2010, p. 315).

The main source of data came from semi-structured interviews that raised questions related to consumer and producer motivations for AFN participation, their experiences and challenges with AFNs, and the reasons behind informants buying food directly from the producer. Of my informants, 20 'formal' recorded interviews were completed, each lasting about $50 \mathrm{~min}$. I was able to re-interview some of the new farmers in my core fieldwork sites. Many more spontaneous (non-recorded) interviews took place as I came across unexpected AFNs on my 'trips' away from my main fieldwork sites and also from my regular attendance to the farmer's market. My thoughts from these spontaneous meetings were recorded in a research diary.

Another source of data used was the translated social media transcripts between the farm Four Season Share and their members. I was able to acquire twenty-two anonymised extracts from 'WeChat' (the Chinese social media equivalent of 'WhatsApp') which had occurred between the farm and its members over a 6-month period in 2016. This rather unique data set provided a great lens to analyse the interactions between the members and the farm and helped triangulate my findings with the interview data and the other secondary sources examined.

For my qualitative data analysis, I used a variant of grounded theory as proposed by O'Brien (2006) for foreign researchers doing social science in China. This method is sensitive to the current theoretical discussions surrounding the issue in question, but allows enough flexibility for empirical data to emerge beyond the constraints of a narrow, and often Western-orientated, theoretical lens. The advantages of this method allows the (Western) researcher to distance themselves from their established theories and to account for China's unique "globalizing, civilising, creolization process...in which Chinese culture is [just] one of the ingredients" (Pieke 2014, p. 125). Such an approach also helps to avoid adopting Western notions of policy and analysis which assume that China, post opening-up, would simply echo the processes of development engendered by
Western political and economic forms. Indeed, China's rise on the international stage should be seen as an invitation for scholars to reassess social phenomena, like AFNs, in a fresh light. As geographers Lenka Fendrychová, and Petr Jehlička (2018, p. 9) have emphasised, this endeavour to address the "geographical knowledge gap" within AFN research, is one that is not only timely, but is also able to "produce novel and relevant conceptualisation".

\section{Findings}

Chinese AFNs operate in a setting which, in contrast to the global north, has poor levels of consumer confidence in both food labelling and small scale producers. This, alongside a heightened general wariness surrounding food safety, has placed a particularly intense burden of trust on Chinese AFN producers. The subsequent onus on producers, to reach out and connect with consumers to form new bonds of trust, was immediately apparent in my fieldwork.

\section{Managing trust in Chinese AFNs}

The delicacy of the methods employed by producers to reach out to consumers often emphasised the trust pressures involved in these AFNs. Speaking to one AFN manager, he told me how he enticed potential members through 'wine and dine' events at his farm, often at great cost (CSA Farmer, March 2017). This one-sided relationship, between producers and their members, also becomes evident through their multiple interactions together. For example, in these social media transcripts, the AFN comes across as desperate to please, suggesting they are the supplicant party in the interactions:

"In fact, we feel sorry for you [CSA member]. You trust us so much and pay us beforehand, but your choice is limited. It will be better in the summer." (Four Season Share WeChat message to customer, April 2016).

"Our farm must be close to our customer because currently the customer is waking-up [to food safety issues], but they don't trust online things, if they have some trust issue we can say ok, come and visit our farm and we can show you. They need to see it and they need to experience it. The trust [issue] is a big situation. It is a common problem in China. So, we need a farm near our customer" (Interview with a CSA farm owner, August 2016).

These exchanges between producers and consumers highlight the urgent need for AFNs in China to organise and optimise their food initiatives specifically around the producer-consumer relationship due to this more intense trust 
Fig. 1 Fresh produce at the farmers market

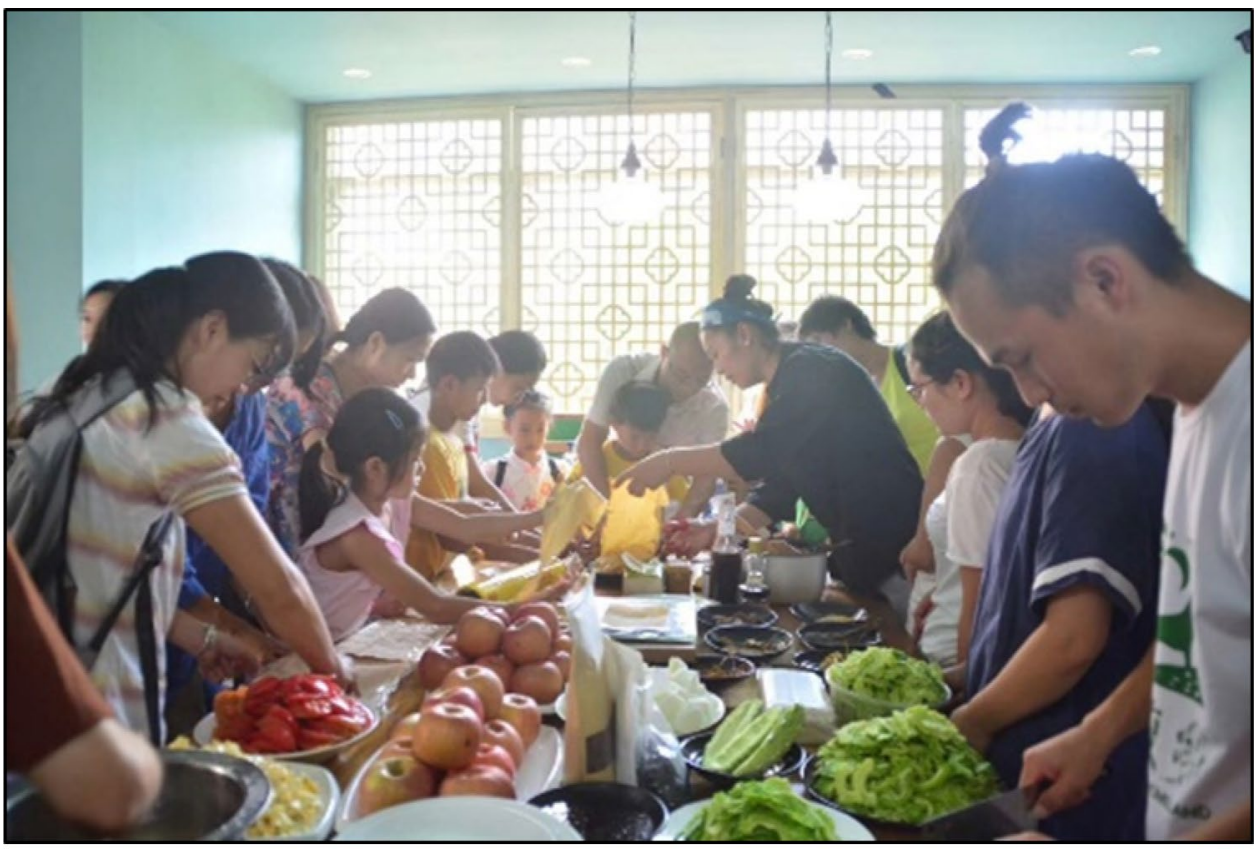

pressure. Indeed, AFN producers in China have been forced to adapt their networks and strategies accordingly. For example, Community Supported Agriculture (CSA) schemes in China have adapted the classic North American CSA model as consumers are less willing to pay large upfront costs. In the US, CSA farms are typically characterised by a sharing of risk between the farmers and their members. The members invest an upfront cost for a season-long subscription for a regularly delivered vegetable box, with an acceptance that the quantity and quality of the produce will vary over the course of a season depending on how well the crops grow. In China, CSAs have had to alter the payment structure-to a more pay-as-you-go format-in order to reduce the risk carried by the more cynical consumer.

Another point of contrast with AFNs from the global north regards attitudes towards brands and appearing modern. This became especially apparent during my fieldwork regarding a food safety incident, 'cherrygate', that affected two different AFNs but posed less of an issue for the larger and more 'modern' farm. Both these two AFN-type enterprises had ordered cherries from the same producer in order to supplement their box scheme. The AFNs were then accused of selling cherries with pesticides based on a 'funny' smell coming from the cherries. The larger, more established and modern appearing 'branded' farm was able to weather the criticism and outrage that occurred on their social media platform, whilst the smaller AFN had to invest in expensive equipment to prove the quality of their cherries in order to maintain and reassure their member base. The cherries were later proved to be organic and the smell was attributed to the plastic containers of the cherries that had started to smell due to exposure to the sun. ${ }^{10}$ This extra scrutiny on the smaller AFN suggests that in China, 'small' is not equated with being 'greener' or more trustworthy.

\section{Forming trust through food}

Whilst social media was important in managing the relationship between the AFN and its members, its central focus was often with the specific material qualities of food, ususally its sense of freshness (xinxin). It was often this quality that shaped the initial motivation for participation in these AFNs in the first place:

".... and I became interested in this organic product after smelling and tasting them, it was just so fresh" (Farmers market attendee, December 2015).

"The organic market. It's great. I joined this platform for maybe 3 or 4 years ago for its fresh produce. At first, I'm just a customer, I buy their product. Then gradually, I get more and more involved and now I'm a vendor here" (Famers Market Vendor, September 2016).

These material qualities are what principally garners consumer interest in Chinese AFNs, as opposed to notions of locality, ecology or socio-political issues, at least in terms of initial participation.

\footnotetext{
${ }^{10}$ Many thanks to fellow researcher Abigail Boc of Yale University for sharing with me her 'Cherrygate' story (2015).
} 
Fig. 2 Banquet at ChengXiangHui

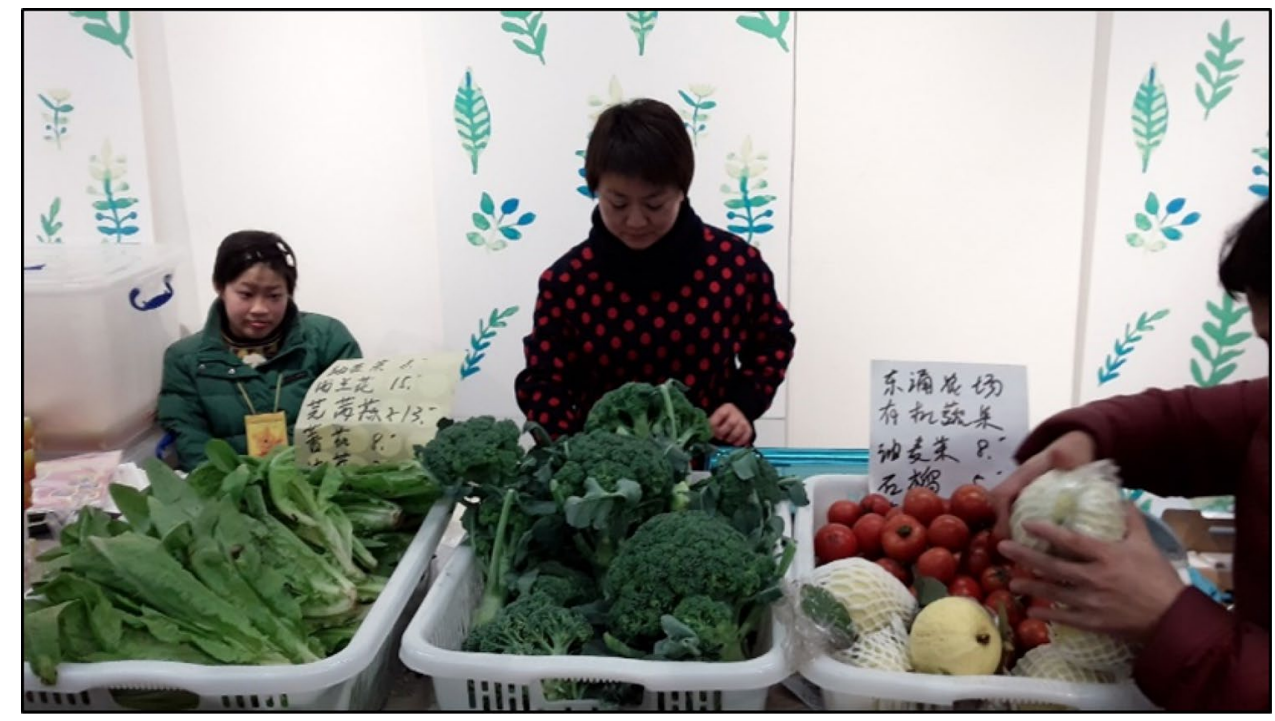

At ChengXiangHui farmers market, there is an emphasis, similar to wet markets, on displaying the 'material' qualities of food as proof of authenticity (see Fig. 1, fresh produce at ChengXiangHui). For example, the farmers market often involved a lunch break allowing buyers to try the free the food on sale. During the break, the qualities of the food are put on a display to showcasing a particular aesthetic of 'freshness' and 'bounteousness' (see Fig. 2).

This tasting activity highlights how the perceived material qualities of the food are what shapes the behaviour of the participants and the outcome of the relationship between buyers and sellers. In other words, ChengXiangHui relies on creating an experience centre around the sensations created by the food materiality. These sensations can allow for an intimacy between the producers and consumers to develop, as the food is tasted, smelt, and touched before purchase. ${ }^{11}$ This experience, that is centred on the material qualities of food, help facilitates trust between participants and the exchange of embedded values. Indeed, the weight given by consumers to these material qualities and the taste of the produce itself is sometimes enough on its own to facilitate trust. In the example below, one member claims he has no need to visit the farm itself to see if they do use ecological techniques, taste alone of the produce is sufficient:

Member: Do you really use organic fertilizers?

FSS (Four Season Share): Of course! I suppose you haven't been to our farm yet?

Member: No, I haven't.

\footnotetext{
11 Whilst it is too early to tell how Covid-19 will impact the food industry in China, it is likely that an increase regulations and general distrust could prove a boon to AFNs as consumer turn to alternative food provisioning channels - but within these AFNs how food is interacted with, namely touch, could also be affected.
}

FSS: Come for visit when you have time and you will trust us after your visit

Member: Its ok. I will know it when I taste it.

(WeChat Transcript Extract, June 2016).

The member in this extract is articulating that it is the materiality of the of the produce which will shape her actions, namely a continuation of her subscription to the farm. It is not trust per se, guiding the member's actions, but rather trust is being co-produced alongside the material quality of the food.

\section{Constructing materiality under trust pressure}

The particular food safety and trust pressure context in China has often meant that Chinese AFNs have to 'construct' the material qualities of their food alongside other strategies in order to negotiate consumer anxieties adequately. For example, Chinese AFNs are especially focused on highlighting that their farming techniques are free of pesticides and chemical fertilisers as food safety is not only a critical marketing point but also a core motivation for those producers for founding these enterprises:

When my child got critically sick from eating unsafe food, that was it, we knew we had to do things differently, so we went to ...back to nature, to grow our own tasty food" (Farmers Market Vendor, November 2015). "I grew up in very good natural environment and I was very lucky that I could have anything tasty from nature as I was born in the rural area. At that time, we could have good food, later I missed the [tasty rural] food but realized I could not find it in the city. So how can I find it back? [I started a CSA]" (CSA owner, Four Season Share, July 2016). 


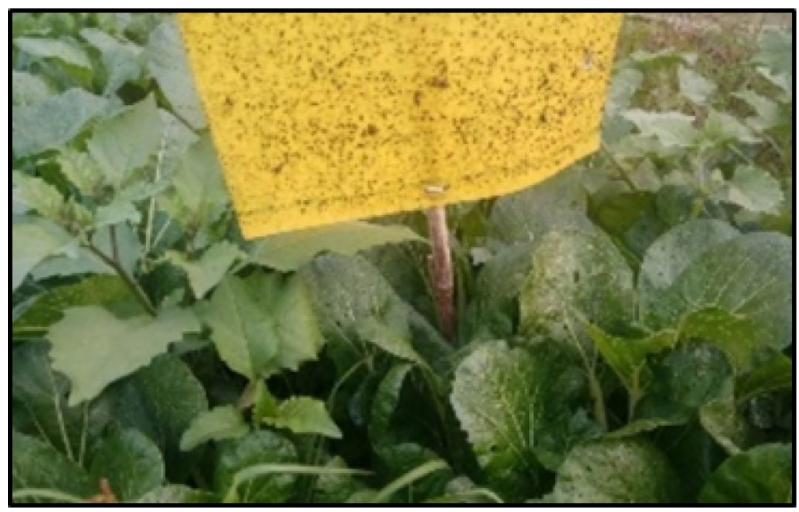

Fig. 3 Bug Stickers, which are used for pesticide control at Four Season Share

To emphasise this food safety aspect, Four Season Share would often stress the technical innovations they use that allow them to farm without utilising chemical inputs-frequently sharing on social media or highlighting these innovations on weekend farm tours. For example, they display to vising members the inventive biological traps they use instead of pesticides (e.g. 'bug stickers' Fig. 3), their large 'hoop houses' (which act as greenhouses that allow the farm to produce out of season food) and the variety of organic fertiliser techniques they utilise. The CCTV cameras dotted around the farm are also noticeable on the farm tours, which allow the members access to a livestream of farming practices when they are at home. This presence of CCTV, whilst a reminder of China's trust pressure, also serves to reassure members of the material qualities they can expect when produce is grown without chemical inputs. In other words, by providing transparent evidence of the ecological methods used, farms form trust by reinforcing the expectations of consumers concerning the material qualities of food.

Managing the consumer expectations of the material qualities using these additional strategies is crucial because material qualities are not necessarily received as positive, hence the sometime necessary display of technical innovations to verify the authenticity of the ecological or organic material qualities. As with the 'cherrygate' story mentioned previously, it was the smell of the cherries that triggered the explosion of discontent on social media, forcing one AFN to buy the necessary equipment to verify the authenticity of the produce. In other words, it is not just the produces' material qualities articulating its 'constructedness', nor do these qualities guarantee truth, it has to be further accompanied with other means - i.e. technical innovations, online newsletters etc. which together creates a complex articulation of its framing. In this next section, I explore the importance of social media in the framing of these material qualities.

\section{Managing trust pressure with social media}

Social media technologies have become important tools to AFNs worldwide. They have been used in AFNs to develop trust, enhance visibility and for facilitating another 'space' for participatory engagement beyond physical direct exchange (Elghannam et al. 2020; Bos and Owen 2016; Press and Arnould 2011). AFNs in China are particularly reliant on assuming current members will invite other relatives or close friends to the scheme once they have verified its 'trustworthiness'. Whilst these forms of 'indirect reciprocity ${ }^{12}$ are occurring via social media in AFNs globally, that Chinese society is particularly structured along informal 'personal networks' (guangxi) of which 'quality' or 'reputation' (suzhi) plays a key role, has made AFNs more dependent on this form of network. In the example below, the member is actively encouraging this form of indirect reciprocity on behalf on the AFN:

Member: I've heard that you're not doing very well (with sales) at the moment. I'm concerned.

FSS: It would help us if your friends also join. I will send them some information tonight. Thanks for sharing their WeChat details with us

Member: It would be helpful if you send them this: [a pic of the member's contract with Four Season Share]

FSS: ok.

Member: You should encourage your customers to help you advertise by posting on WeChat moments. You can use my moments as an example. ${ }^{13}$

FSS: Thank you. I've got things ready to post: [a series of pictures]

(WeChat Transcript, March 2016).

Through social media, consumers can share their AFN experiences to a wide (and typically similar) audience quickly, whilst also granting them the means to take into account the comments and recommendations made by other users. Thus social media serves as a means for AFNs to build their reputation as a 'trustworthy' through these online exchanges of indirect reciprocity.

\section{Social media and the material qualities of food}

The importance of social media is also evident at Four Season Share where there is an office of approximately nine staff devoted to maintaining this online social media relationship with their members. Through this medium, practical

\footnotetext{
12 'Indirect reciprocity' refers to consumers using the trust or relationships formed by a third party to inform their decision to participate in AFNs (see Wang et al. 2015)

13 WeChat 'moments' is a feature similar to Facebooks 'wall' which allows for postings to be communal.
} 
information is communicated to the consumer: concerning what produce is available; the time by which orders need to be made and information on how to use website. Its key role, though, is to facilitate continuous direct exchange with the member, usually regarding the material qualities of food (and the farm) that may have been recently received (or experienced) by the member. This emphasis on the material qualities of food is necessary as it is through this medium that trust is generated, by coupling consumer interest and awareness with the commodity itself.

This careful negotiation of material qualities by producers is often required as they are not always positively perceived by customers. In the case of the food having "unusual" qualities, that could potentially be off putting to consumers, the farm would pre-empt the unusual characteristic-usually before the food even arrives-in order to assuage their member's concerns. In one example regarding strawberries, a fruit that has been frequently implicated in food scandals, the farm pre-empts its surprising taste:

FSS: Sure. We will deliver every Thursday. The strawberries we have this year are a bit sour, does your kid like it? Has he tried them yet?

Member: Yes! As long as it has no pesticides.

(WeChat Transcript Extract, May 2016).

However, the farm is not always successful in this management of consumer expectations regarding the material qualities of food. In this next example, the member unsubscribed from the farm due to a negative perception of the food's material qualities:

FSS: Mrs. Zheng, regarding your feedback that the ChoySum [Chinese vegetable] is inedible, I've just checked the warehouse yesterday, I don't think the blooming of the flower is enough to affect eating.

FSS: I'll ask my colleague in product department again, please hold on.

Member: They're very old if they have bloomed to this extent. The flower bit would taste bitter if we tried to fry and eat it. Maybe your colleagues have special taste buds

Member: The quality of the vegetables is too bad for my family and really affects eating.

Member: can I unsubscribe please?

(WeChat Transcript, April 2016).

In this exchange, the un-subscription to the farm was a result of the food's material qualities which did not fulfil the consumer's expectations. Material qualities can therefore also cause a reduction of trust and a broken producer consumer relationship, suggesting that this trust, when based on material qualities, is somewhat precarious.

These examples demonstrate that whilst taste and other material qualities are core to the functioning of AFNs, taste alone does not drive AFN participation. Blind taste tests, for example, have shown how difficult it is for consumers to discern between organic and conventional produce. Indeed, often taste and associated material qualities have to be coconstructed with other elements if they are to alter the daily habits, behaviours and the 'ideals' of consumers (and producers) in ways that challenge the conventional food system. AFN farms in China have to assuage consumer fears over the unexpected 'qualities' of the food produce-often they will send pictures of the harvest to explain and justify why produce appears 'sub-standard' that week (perhaps from the result of pests, flooding or drought)—which can only be done conveniently through social media.

\section{Discussion}

As the empirical data above illustrates, trust is often a prerequisite for participation -both initial and continued-and in an environment of trust pressure, it has to be carefully cultivated by the AFN. For AFN research, this aspect is potentially liberating from the perspective of the scholar as in China, due to the intense trust pressure in society (particularly concerning food), there is little or no expectation for a positive 'reconnecting' outcome to emerge from direct exchange. This prevents any inclination for AFN scholars in China to implicitly assume direct exchange leads to, or encourages, a positive outcome in their empirical research - a tendency highlighted in global north orientated AFN literature (Mount 2012; Thorsøe and Kjeldsen 2016). Indeed, there was frequently a sense of angst from the producers when they were talking about attracting members and developing their enterprises into financially secure positions. Whilst the producers generally felt enthusiastic about their enterprises and were convinced about the social and ecological benefits of growing and selling 'greener' and safe food, their prime focus was to design their AFNs around alleviating consumer concerns.

Strategies used by AFNs to alleviate trust pressure ranged from hosting farm visits, 'wine and dine' membership events and by creating the appearance of being modern. These strategies are a response to the tendency in China for consumers to blame individuals, manufacturers and government regulatory bodies in China-as opposed to modern 'branded' companies-and highlights the 'Holy Grail' status given to modernisation (Yan 2015, p. 281-282). Indeed, as the example of 'cherrygate' highlighted, the issue of food safety in China has tended towards a doubling down on trusting famous 'modern appearing' brands, in which only the large, and 'seemingly' reputable, companies can establish (Veeck et al. 2008). This example inverts Western expectations that would generally expect members to show solidarity with the smaller-scale, more personable AFNs that tend to be valorised in the global north (Nost 2014; Le Velly and Dufeu 2016). 
Many of the strategies outlines above tend to alleviate trust by celebrating the material qualities of the AFN's produce. As consumer participation is primarily centred on the texture, taste of the produce and the sense of nostalgia it oft time evokes, it is through these material qualities, which goes beyond taste, that trust often becomes mediated. Uniting all these material elements was the notion of "freshness"- the sense of immediacy between harvesting and consumption-which in Chinese food culture has a strong correlation with perceptions of "good taste, levels of purity, and implied nutritional value" (Zhong et al. 2020, p. 179). This onus on presenting food as fresh, and the associated connotations of taste, purity and nutritional health, has therefore emerged as a core strategy for many Chinese AFNs to mitigate the trust pressure they are under.

The emphasis on the material qualities of food in Chinese AFNs has pushed producers to devote much time to managing the consumers' expectation of the sometimes unusual aspects of organic produce - which is often quite variable in regard to taste and appearance. Managing these expectations is difficult in face of conventional food networks, where consumers trust produce because it is presented as being same every time, shaping and influenced Chinese eating habits accordingly. In China, these habits have typically manifested as a "preference for lean pork, tender crisp fresh vegetables, 'the bigger the better', and evaluations of quality based on the appearance of fruit and vegetables" (Zhang and Qi 2019, p. 126). AFNs, on the other hand, require "a market structured around an open taste, a taste for uncertainty, [which] depends on the cultivation of consumers who choose ecologically embedded products not in spite of their variability, but because of it (emphasis in original)" (Krzywoszynska 2015, p. 500). Thus, Chinese AFNs often have to work hard in this regard as not only must they cultivate consumers to accept produce variability, but do so under circumstances of increased trust pressure.

The careful and deliberate emphasis of foods material qualities by many Chinese AFNs is fundamental to creating trust between producer and consumer, hence its careful construction. It is through various technical interventions, careful presentation, banqueting, farm visits and online media that freshness and the tactile qualities of produce are emphasised and used to reassure consumers of the foods quality i.e. safety. In particular, this 'constructedness' is done principally through social media, a medium which has become ubiquitous in China for its ability to facilitate the networked "consumer-display-based individualization" that has slowly become endemic to Chinese society the more it has embraced globalised neoliberalism (Tyfield 2017; Yu 2014) ${ }^{14}$ In terms of food, social media in China is

\footnotetext{
14 'Consumer-display-based individualization' is a form of conspicuous consumption that works as 'conspicuous achievement' in which one's consumption choices are often articulated as 'a badge of one's personal (even moral) merit' (Tyfield 2017, P. 136).
}

frequently used to highlight one's diet, with organic, green and expensive foodstuffs seen as markers of 'class' (suzhi) (Klein 2015).

This importance of social media to Chinese AFNs has already been noted with Sarah Zhang \& Zhixing Zhang's (2012) research on the 'Little Donkey' farm-China's first major CSA initiative. Their study highlights the importance of social media in establishing a more personal form of communication by arguing that since micro blogging is "convenient", "instant", "accessible" and an "embedded" form of social networking it can facilitate a viable and immediate platform to foster the necessary (i.e. 'trusting') producer-consumer interaction for AFN projects to work (Zhang and Zhang 2012) - a crucial factor when considering the distances sometimes involved between consumer and producer.

I would argue, however, that it is the ability of social media to help verify and explain the material qualities of food which is perhaps its most salient attribute-especially in China due to the form of trust pressure its AFNs operate under. By embedding produce in a broader informational context, uncertain material qualities (or risks) that may be tasteless or invisible, can be contextualised. Indeed, it is this ability of social media to celebrate the unusual material qualities of organic produce which becomes paramount to the functioning of AFNs.

This process of reassurance via social media is crucial for the mediation of the Chinese trust pressure as it facilitates the positive and trust-reinforcing aspects central to AFNs and leads to more embedded forms of exchange. Indeed, that both positive and negative (i.e. cherrygate) information can be disseminated along these networks, potentially pushing consumers away from 'untrustworthy' vendors, social media "may also bring a risk for companies that do not properly manage their relationship with their customers, as negative motivations are more likely to generate user response than positive motivations" (Elghannam et al. 2020, p. 11). In Chinese AFNs, the immediacy lent by social media is in many ways required to negotiate the immediate freshnessand its uncertainties - of the produce that the trust based relationship is dependent on. The critical role social media plays in negotiating this materiality and the forms of indirect reciprocity present in Chinese AFNs suggest that it is the network aspect of Chinese AFNs which is key - a difference from the 'alternative' emphasis in U.S. AFNs and the emphasis on 'food' found in European AFNs (Watts et al. 2005; Martindale et al. 2018). 


\section{Conclusion}

Chinese case studies are particular apt at demonstrating that trust is not an outcome of direct exchange in AFNs per se, but is often mediated and negotiated through the food itself. This is in keeping with recent scholarship which argues that trust, in AFN analysis "should not be perceived as the objective of AFNs, but rather it should be perceived as a mechanism which enables the network to function" (Thorsøe and Kjeldsen 2016, p. 171). These insights are especially illuminated in China due to the particular form of trust pressure AFNs are under there and the almost complete dependence they have on celebrating and managing the material qualities of their produce to succeed as initiatives. This trust pressure is particularly manifest in a food industry that has been predominantly shaped around quantity over quality policies and has consequently become rife with food safety issues and has undermined trust in food certification. For AFN producers the burden of this trust pressure is particularly acute in comparison to their global north counterparts and they have had to adapt their enterprises accordingly.

This adaption has come in the form of developing a consumer-centric approach that can cater to the cynicism and neediness of Chinese consumers regarding the properties of the produce. Whilst on the surface this has resulted in instrumental producer-consumer relationships (i.e. the search for safe food) it has also created food networks centred around the material qualities of food. To facilitate this celebration of material qualities many Chinese AFNs have had to construct almost their entire apparatus around making these qualities visible. They have used a wide variety of tools to achieve this, CCTV, tasting sessions, farm visits and deploying technical innovations that highlight ecological farming approaches. Crucially, however, it's the immediacy lent by social media which has been the most effective in this regard of celebrating material qualities. Social media facilitates both the accentuation of qualities like seasonality and freshness and when necessary, qualifies the uncertain aspects the materiality of organic produce also encompasses.

This celebration of taste, freshness, and the tactile qualities of food is potentially quite liberating as recent AFN literature has begun to emphasise material qualities as the key aspect regarding the 'transformational' potential in AFNs (Turner and Hope 2015; Watts et al. 2018) - as opposed to the practice (and proximity) of direct exchange alone developing the moral, social and ecological based connections between producers and consumers (Mount 2012; Thorsøe and Kjeldsen). In other words, it is the materiality of food that is often key in coproducing a trusting relationship between producers and consumers.

There is a potential here, as supported by recent quantitative research in Italian AFNs, for social media use in
AFNs to positively affect sustainable behaviour change in both the purchasing and consumption practices of participants (De Bernardi et al. 2019). This is perhaps an improvement to the on-site physical exchange of 'embedded values', which is only tending to shape purchasing behaviours (De Bernardi et al. 2019). In other words, this construction of food materiality through social media can also pave the way for foods revaluing. Indeed, it is often through the social media led discussions on the material qualities of food that will lead into producer-consumer exchanges regarding food storage ideas, cooking methods, recipes and other discussions regarding the everyday practices centred around food. It is from these forms of exchanges that produce becomes more than a good for barter, as awareness can also be potentially raised concerning wider food issues (Clarke et al. 2008; Dowler et al. 2009; Turner and Hope 2015).

This focus on material qualities of AFN produce compliments the recent 'territorial' approach to AFN research that emphasises how these networks should not be studied in isolation, but rather as one type of initiative in a larger landscape of networks (Lamine et al. 2019). As this landscape also includes 'quality' food networks and specialty products alongside AFNs, they all contribute to having a cumulative effect on inducing conventional actors to adapt and change some of their practices (Lamine et al. 2019; Leggett 2017). In other words, public action is influenced by an increased recognition of food issues that all these networks, to varying degrees, promote. And it is often through the material qualities of food, embodied by all these various 'alternative' procurement options, that this recognition becomes possible.

Acknowledgements My sincerest gratitude goes to all the individuals and Chinese 'new farmers' who have shared their stories with me. My appreciation also goes to EU's I-RICE project 'SEW-REAP', my host institution in China, the 'Guangzhou Institute of Geochemistry', and the ESRC, for funding and facilitating this study that was part of my Lancaster University PhD. A deep thanks also to Nigel Clark, David Tyfield, Gan Zhang and the journal reviewers for their support and input.

\section{References}

Albrecht, C., and J. Smithers. 2018. Reconnecting through local food initiatives? Purpose, practice and conceptions of 'value'. Agriculture and Human Values 35 (1): 67-81.

Alkon, A.H. 2013. The socio-nature of local organic food. Antipode 45 (3): 663-680.

Allen, P., M. Fitzsimmons, M. Goodman, and K. Warner. 2003. Shifting plates in the agrifood landscape: the tectonics of alternative agrifood initiatives in California. Journal of Rural Studies 19 (1): $61-75$.

Bos, E., and L. Owen. 2016. 'Virtual Reconnection': the online spaces of alternative food networks in England. Journal of Rural Studies 45: 1-14. 
Clarke, N., P. Cloke, C. Barnett, and A. Malpass. 2008. The spaces and ethics of organic food. Journal of Rural Studies 24 (3): 219-230.

Cortazzi, M., N. Pilcher, and L. Jin. 2011. Language choices and "blind shadows": investigating interviews with Chinese participants. Qualitative Research 11 (5): 505-535.

De Bernardi, P., A. Bertello, and F. Venuti. 2019. Online and on-site interactions within alternative food networks: Sustainability impact of knowledge-sharing practices. Sustainability 11 (5): 1457.

Dowler, E., M. Kneafsey, R. Cox, and L. Holloway. 2009. "Doing food differently": Reconnecting biological and social relationships through care for food. Sociological Review 57 (2): 200-221.

Ekers, M., C.Z. Levkoe, S. Walker, and B. Dale. 2016. Will work for food: agricultural interns, apprentices, volunteers, and the agrarian question. Agriculture and Human Values 33 (3): 705-720.

Elghannam, A., F.J. Mesias, M. Escribano, L. Fouad, A. Horrillo, and A.J. Escribano. 2020. Consumers' Perspectives on Alternative Short Food Supply Chains Based on Social Media: A Focus Group Study in Spain. Foods 9 (1): 22.

Ely, A., S. Geall, and Y. Song. 2016. Sustainable maize production and consumption in China practices and politics in transition. Journal of Cleaner Production 134: 259-268.

Fendrychová, L., and P. Jehlička. 2018. Revealing the hidden geography of alternative food networks: The travelling concept of farmers' markets. Geoforum 95: 1-10.

Gaudreau, M. 2019. State food security and people's food sovereignty: competing visions of agriculture in China. Canadian Journal of Development Studies/Revue canadienne d'études du développement 40 (1): 12-28.

Goodman, D., E.M. DuPuis, and M. Goodman. 2012. Alternative food networks: knowledge, practice, and politics. London: Routledge.

Giddens, A. 1990. The consequences of modernity. Stanford: Stanford University Press.

Hale, M. 2013. Tilling sand: contradictions of "'Social Economy”' in a Chinese movement for alternative rural development. Dialectical Anthropology 37: 51-82.

Harris, E.M. 2010. Eat Local? Constructions of Place in Alternative Food Politics. Geography Compass 4: 355-369.

Hayden, J., and D. Buck. 2012. Doing community supported agriculture: Tactile space, affect and effects of membership. Geoforum 43 (2): 332-341.

He, X. 2007. New Rural Construction and the Chinese Path. Chinese Sociology and Anthropology 39 (4): 26-38.

He, B., Z. Yun, J. Shi, and G. Jiang. 2013. Research progress of heavy metal pollution in China: sources, analytical methods, status, and toxicity. Chinese Science Bulletin 58 (2): 134-140.

Hinrichs, C.C. 2003. The practice and politics of food system localization. Journal of Rural Studies 19 (1): 33-45.

Holloway, L., M. Kneafsey, L. Venn, R. Cox, E. Dowler, and H. Tuomainen. 2007. Possible food economies: A methodological framework for exploring food production-consumption relationships. Sociologia Ruralis 47 (1): 1-19.

Ilbery, B., and D. Maye. 2005. Alternative (shorter) food supply chains and specialist livestock products in the Scottish-English borders. Environment and Planning A 37: 823-844.

Jarosz, L. 2008. The city in the country: Growing alternative food networks in metropolitan areas. Journal of Rural Studies 24 (3): 231-244.

Jiao, X., N. Mongol, and F. Zhang. 2018. The transformation of agriculture in China: Looking back and looking forward. Journal of Integrative Agriculture 17 (4): 755-764.

Jin, X., Y. Shao, Z. Zhang, L.M. Resler, J.B. Campbell, G. Chen, and Y. Zhou. 2017. The evaluation of land consolidation policy in improving agricultural productivity in China. Scientific Reports 7 (1): 2792.
Kahn, M.E., and S. Zheng. 2016. Blue skies over Beijing: economic growth and the environment in China. Princeton: Princeton University Press.

Kendall, H., S. Kuznesof, M. Dean, M.Y. Chan, B. Clark, R. Home, and L. Frewer. 2019. Chinese consumer's attitudes, perceptions and behavioural responses towards food fraud. Food Control 95: $339-351$.

Kirwan, J. 2006. The interpersonal world of direct marketing: examining conventions of quality at UK farmers' markets. Journal of Rural Studies 22 (3): 301-312.

Klein, J.A. 2015. Eating green: Ecological food consumption in urban China. In Re-Orienting Cuisine: East Asian Foodways in the Twenty-First Century, ed. K. Kim, 238-262. New York: Berghahn Books.

Klein, J.A. 2014. Connecting with the Countryside? "Alternative" food Movements with Chinese Characteristics. In Ethical Eating in the Postsocialist and Socialist World, ed. Y. Ung, J.A. Klein, and M.L. Caldwell, 116-139. California: University of California Press.

Klein, J.A. 2009. Creating ethical food consumers? Promoting organic foods in urban Southwest China. Social Anthropology 17 (1): 74-89.

Kneafsey, M., R. Cox, L. Holloway, E. Dowler, L. Venn, and H. Tuomainen. 2008. Reconnecting consumers, producers and food: exploring alternatives. New York: Berg.

Krul, K., and P. Ho. 2017. Alternative approaches to food: Community supported agriculture in urban China. Sustainability 9 (5): 844.

Krzywoszynska, A. 2015. Wine is not Coca-Cola: marketization and taste in alternative food networks. Agriculture and Human Values 32 (3): 491-503.

Lam, H.M., J. Remais, M.C. Fung, L. Xu, and S.S.M. Sun. 2013. Food supply and food safety issues in China. The Lancet 381 (9882): 2044-2053.

Lamine, C., L. Garçon, and G. Brunori. 2019. Territorial agrifood systems: A Franco-Italian contribution to the debates over alternative food networks in rural areas. Journal of Rural Studies 68: 159-170.

Lai, L. 2014. The Local Intimacies of Chinas' Rural-Urban Divide. Positions 22 (3): 543-550.

Lee, R. 2000. Shelter from the storm? Geographies of regard in the worlds of horticultural consumption and production. Geoforum 31 (2): 137-157.

Leggett, A. 2017. Bringing green food to the Chinese table: How civil society actors are changing consumer culture in China. Journal of Consumer Culture 20 (1): 83-101.

Le Velly, R. 2019. Allowing for the projective dimension of agency in analysing alternative food networks. Sociologia Ruralis 59 (1): $2-22$.

Le Velly, R., and I. Dufeu. 2016. Alternative food networks as "market agencements": Exploring their multiple hybridities. Journal of Rural Studies 43: 173-182.

Lin, H., P. Fang, L. Zhou, and L. Xu. 2019. A relational view of selfprotection amongst China's food safety crises. Canadian Journal of Development Studies/Revue canadienne d'études du développement 40 (1): 131-142.

Malpass, A., Barnett, C., Clarke, N., \& Cloke, P. 2007. Problematizing Choice: Responsible Consumers and Sceptical Citizens. In Governance, Consumers and Citizens, eds. M. Bevir., F. Trentmann, 231-256. London: Palgrave Macmillan UK.

Martindale, L., R. Matacena, and J. Beacham. 2018. Varieties of alterity: Alternative food networks in the UK, Italy and China. Sociologia Urbana e Rurale 115: 27-41.

McClintock, N. 2014. Radical, reformist, and garden-variety neoliberal: coming to terms with urban agriculture's contradictions. Local Environment 19 (2): 147-171.

Mount, P. 2012. Growing local food: scale and local food systems governance. Agriculture and Human Values 29 (1): 107-121. 
Nost, E. 2014. Scaling-up local foods: Commodity practice in community supported agriculture (CSA). Journal of Rural Studies 34: $152-160$.

O’Brien, K. 2006. Discovery, Research (Re)design, and Theory Building. In Doing fieldwork in China, ed. M. Heimer and S. Thøgersen, 27-41. Copenhagen: NIAS Press.

Opitz, I., K. Specht, A. Piorr, R. Siebert, and I. Zasada. 2017. Effects of consumer-producer interactions in alternative food networks on consumers' learning about food and agriculture. Moravian Geographical Reports 25 (3): 181-191.

Ostrom, M., and R. Jussaume. 2007. Assessing the significance of direct farmer-consumer linkages as a chance strategy in Washington state: civic or opportunistic. In Remaking the North American Food System, ed. C. Hinrichs and T. Lyson, 235-259. Nebraska: University of Nebraska Press.

Paull, J. 2008. The Greening of China's Food - Green Food, Organic Food and Eco-labelling. Paper at: Sustainable Consumption and Alternative Agri-Food Systems Conference, Liege University, Arlon, Belgium, 27 - 30 May 2008.

Pieke, F.N. 2014. Anthropology, China, and the Chinese Century. Annual Review of Anthropology 43: 123-138.

Pinna, S. 2017. Alternative farming and collective goals: Towards a powerful relationships for future food policies. Land Use Policy 61: 339-352.

Preiss, P., F. Charão-Marques, and J.S. Wiskerke. 2017. Fostering Sustainable Urban-Rural Linkages through Local Food Supply: A Transnational Analysis of Collaborative Food Alliances. Sustainability 9 (7): 1155.

Press, M., and E.J. Arnould. 2011. Legitimating community supported agriculture through American pastoralist ideology. Journal of Consumer Culture 11 (2): 168-194.

Roe, E.J. 2006. Things becoming food and the embodied, material practices of an organic food consumer. Sociologia Ruralis 46 (2): 104-121.

Renting, H., T.K. Marsden, and J. Banks. 2003. Understanding alternative food networks: exploring the role of short food supply chains in rural development. Environment and planning A 35 (3): 393-411.

Rosol, M. 2020. On the Significance of Alternative Economic Practices: Reconceptualizing Alterity in Alternative Food Networks. Economic Geography 96 (1): 52-76.

Riggs, P. 2005. A Different Growing Season South of the Mountains: Guangdong Province Rethinks Its Agricultural Development Model. China Environment Series 7: 47-54.

Sage, C. 2003. Social embeddedness and relations of regard: alternative 'good food' networks in south-west Ireland. Journal of Rural Studies 19 (1): 47-60.

Schneider, M. L., \& Sharma, S. 2014. China's Pork Miracle?: Agribusiness and Development in China's Pork Industry. EUR-ISS-PER.

Scott, S., Z. Si, T. Schumilas, and A. Chen. 2018. Organic food and farming in China: Top-down and bottom-up ecological initiatives. New York: Routledge.

Scott, S., Z. Si, T. Schumilas, and A. Chen. 2014. Contradictions in state- and civil society-driven developments in China's ecological agriculture sector. Food Policy 45: 158-166.

Selfa, T., and J. Qazi. 2005. Place, taste, or face-to-face? Understanding producer-consumer networks in "local" food systems in Washington State. Agriculture and Human Values. https://doi.org/10.1007/ s10460-005-3401-0.

Shi, Y., C. Cheng, P. Lei, T. Wen, and C. Merrifield. 2011. Safe food, green food, good food: Chinese Community Supported Agriculture and the rising middle class. International Journal of Agricultural Sustainability 9 (4): 551-558.

Si, Z., T. Schumilas, and S. Scott. 2015. Characterizing alternative food networks in China. Agriculture and Human Values 32 (2): 299-313.
Sim, A., \& Yang, Y. 2016. China: An overview of the new food safety law. Food Safety Magazine Available at https://www.foodsafety magazine.com/enewsletter/china-an-overview-of-the-new-foodsafety-law/ Accessed 10 April 2018.

Simon, S. 1996. Gender in Translation: Cultural Identity and the Politics of Transmission. London: Routledge.

Smithers, J., J. Lamarche, and A.E. Joseph. 2008. Unpacking the terms of engagement with local food at the farmers' market: Insights from Ontario. Journal of Rural Studies 24 (3): 337-350.

Tang, W. 2016. Populist authoritarianism: Chinese political culture and regime sustainability. Oxford: Oxford University Press.

Temple, B., and A. Young. 2004. Qualitative Research and Translation Dilemmas. Qualitative Research 4 (2): 161-178.

Thorsøe, M., and C. Kjeldsen. 2016. The constitution of trust: Function, configuration and generation of trust in alternative food networks. Sociologia Ruralis 56 (2): 157-175.

Turner, B., and C. Hope. 2015. Staging the Local: rethinking scale in farmers' markets. Australian Geographer 46 (July): 147-163.

Turner, B. 2014. Taste and Lively Matter in the Anthropocene. $M / C$ Journal, 17(1). https://journal.mediaculture.org.au/index.php/ mcjournal/article/viewArticle/769 Accessed 15 November 2015.

Turner, B. 2011. Embodied connections: sustainability, food systems and community gardens. Local Environment 16 (6): 509-522.

Tyfield, D. 2017. Liberalism 2.0 and the Rise of China. London: Routledge.

Van Nes, F., T. Abma, H. Jonsson, and D. Deeg. 2010. Language differences in qualitative research: Is meaning lost in translation? European Journal of Ageing 7 (4): 313-316.

Veeck, A., H. Yu, and A.C. Burns. 2010. Consumer risks and new food systems in urban China. Journal of Macromarketing 30 (3): 222-237.

Wang, R.Y., Z. Si, C.N. Ng, and S. Scott. 2015. The transformation of trust in China's alternative food networks: disruption, reconstruction, and development. Ecology and Society 20 (April): 19.

Watts, D., J. Little, and B. Ilbery. 2018. 'I am pleased to shop somewhere that is fighting the supermarkets a little bit'. A cultural political economy of alternative food networks. Geoforum 91 : 21-29.

Winter, M. 2003. Embeddedness, the new food economy and defensive localism. Journal of Rural Studies 19 (1): 23-32.

Whatmore, S., P. Stassart, and H. Renting. 2003. What's alternative about alternative food networks? Environment and Planning $A$ 35 (3): 389-391.

Wu, L., 2016. The Invisible Wound: The Long Term Impact of China's Cultural Revolution on Trust. San Francisco, American Economic Association Annual Meeting. https://www.semanticscholar.org/ paper/The-Invisible-Wound\%3A-The-Long-Term-Impact-of-onWu/08f6cf02655c25a02d7bd33372221ee3182d6689 Accessed 06 August 2020.

Xu, W. 2017. Expert sounds alarm on pesticide overuse, ChinaDaily. https://www.chinadaily.com.cn/china/2017-01/23/content_28030 533.htm Accessed 18 June 2017.

Yan, Y. 2015. From food poisoning to poisonous food: The spectrum of food-safety problems in contemporary China. In Re-Orienting Cuisine: East Asian Foodways in the Twenty-First Century, ed. K. Kim, 263-286. New York: Berghahn Books.

Yang, G. 2013. Contesting food safety in the Chinese media: Between hegemony and counter-hegemony. The China Quarterly 337-355.

Yu, L. 2014. Consumption in China. Cambridge: Polity.

Zhang, S. Y., \& Zhang, Z. 2012. Leveraging Micro Blogging to Build Trust by Community Supported Agriculture (CSA) Pioneers in China. GlobDev 15.

Zhang, L., and G. Qi. 2019. Bottom-up self-protection responses to China's food safety crisis. Canadian Journal of Development Studies/Revue canadienne d'études du développement 40 (1): 113-130. 
Zhang, L., Y. Xu, P. Oosterveer, and A. Mol. 2016. Consumer trust in different food provisioning schemes evidence from Beijing. China. Journal of Cleaner Production 134 (1): 269-279.

Zhong, S., M. Crang, and G. Zeng. 2020. Constructing freshness: the vitality of wet markets in urban China. Agriculture and Human Values 37 (1): 175-185.

Publisher's Note Springer Nature remains neutral with regard to jurisdictional claims in published maps and institutional affiliations.
Leigh Martindale Dr Leigh Martindale was a Research Associate at Lancaster Environmental Centre, Lancaster University. He has published academic articles on 'Alternative Food Networks' and the Anthropocene and is currently researching China's concept of Ecological Civilization. He is due to start a postdoc position at Sun Yat-Sen university in Guangzhou, China in December 2020. 